\title{
Evaluation the Diagnostic Values of Direct and Indirect Non-invasive Biochemical Markers of Liver Fibrosis in Patients with Chronic Hepatitis B Virus
}

\author{
Dawood Salman Mahdi ${ }^{1}$, Hamid Jaddoa Abbas ${ }^{2}$ and Mostafa Salman Hasan ${ }^{3}$ \\ \{dr.dawds@stu.edu.iq $\left.{ }^{1}\right\}$ \\ Southern Technical University, Health and Medical technology College. Iraq, Basra ${ }^{1}$ \\ Al-Faiha'a Teaching Hospital, Iraq, Basra ${ }^{2}$
}

\begin{abstract}
To investigate hepatic fibrosis in chronic hepatitis B patients using non-invasive direct and indirect biomarkers, as well as to assess the diagnostic accuracy of these biomarkers. There are 119 people in a case-control study: 50 healthy people served as controls, whereas 69 individuals with chronic hepatitis B were diagnosed using the PCR method. In addition to cholesterol, the direct biomarkers (serum fibronectin, haptoglobin, and TNF alpha) and indirect biomarkers (serum total bilirubin, direct bilirubin, aspartate aminotransferase AST, alanine aminotransferase ALT, alkaline phosphatase ALP, albumin, and gamma-glutamyl transferase - GGT) are For liver function tests and a fibrotic marker, there was a significant difference $(\mathrm{P}<0.05)$ between control and HBV patients: fibronectin (168.56 \pm 98.47 control vs. $98.24 \pm 74.87 \mathrm{HBV})$ and TNF alpha $(121.96+124.8$ control vs. $56.03 \pm 48.39 \mathrm{HBV})$. The haptoglobin and cholesterol revealed no differences between males or females when compared with control. The sensitivity of fibrotic markers: fibronectin, TNF alpha, and haptoglobin cannot be calculated. These biomarkers could be used instead of a liver biopsy to track the progression and therapy of liver fibrosis.
\end{abstract}

Keywords: Hepatitis B virus, liver fibrosis, Liver Biopsy.

\section{Introduction}

The creation of an excessive quantity of scar tissue in the liver is known as hepatic fibrosis. It occurs when the liver strives to repair and replace damaged cells. The liver can be injured by a variety of factors. Fibrosis itself causes no symptoms, but severe scarring can lead to cirrhosis. The persistence of liver viral infection causes chronic damage and excessive extracellular matrix formation by hepatic stellate cells in the liver, which can lead to cirrhosis and malignancy. The liver is a multilobed reddish-brown glandular organ that occupies most of the upper right section of the human abdominal cavity, just below the diaphragm. It is in charge of metabolism, immunity, digestion, detoxification, and storage, among other things [1]. It also has the responsibility of regulating the flow and safety of substances absorbed from the digestive system prior to their distribution to the systemic circulatory system. The importance of the liver is reflected by the fact that complete loss of hepatic function can result in death within minutes [2]. Hepatitis is an inflammation of the liver which results in damage to hepatocytes with subsequent cell death (necrosis) [3]. Liver fibrosis is a complicated fibrogenic and inflammatory process that develops as a result of chronic liver injury and is a precursor to liver cirrhosis [4]. 


\section{Materials and Methods}

119 participants took part in the case-control study: 50 healthy controls ( 26 men and 24 women) and 69 patients with chronic hepatitis type B for at least 6 months ( 36 males and 33 females). Al-Faiha'a Gastrointestinal Centre in Barah, Iraq, treated the patients. Full clinical examinations and laboratory tests were used to diagnose the patients. The Patients, who had chronic diseases except for patients in our study were excluded from the study. The parameters Haptoglobin is the measurement by Abbott C4000 autoanalyzer. The ELISA technique was used to measure fibronectin and TNF alpha. Cobas INTEGRA plus 400 auto analysers for liver function testing and cholesterol measurement.

\subsection{Statistical Analysis}

Statistical significance was defined as p-values less than 0.05 using IBM SPSS Statistics 22.0.

\section{Results}

\subsection{Control and Hepatitis B Patients}

This work was observed that the age, sex, and haptoglobin did not show statistical differences between the control group and hepatitis B patients ( $\mathrm{P}$-value $>0.05)$, While all the other variables were shown significant differences $(\mathrm{P}<0.05)$ as represented in Table 1.

Table 1. Data on healthy people and individuals with hepatitis B.

\begin{tabular}{|c|c|c|c|}
\hline Variables & $\begin{array}{l}\text { Control } \\
(\mathrm{N}=50)\end{array}$ & $\begin{array}{c}\text { Hepatitis B } \\
(\mathrm{N}=69)\end{array}$ & P-Value \\
\hline Age & $42.2 \pm 15.7$ & $43.0 \pm 15.9$ & 0.784 \\
\hline Male & $36(52.2 \%)$ & $26(52.0 \%)$ & 0.912 \\
\hline Female & $33(47.8 \%)$ & $24(48.0 \%)$ & \\
\hline Total & $69(100 \%)$ & $50(100 \%)$ & \\
\hline Bilirubin- T & $0.41 \pm 0.17$ & $2.58 \pm 2.27$ & 0.0001 \\
\hline AST & $16.24 \pm 4.61$ & $60.37 \pm 56.11$ & 0.0003 \\
\hline ALT & $29.90 \pm 10.26$ & $74.73 \pm 71.5$ & 0.0002 \\
\hline ALP & $75.12 \pm 15.09$ & $115.4 \pm 73.78$ & 0.0001 \\
\hline GGT & $17.65 \pm 7.81$ & $88.19 \pm 83.06$ & 0.0001 \\
\hline Albumin & $4.28 \pm 0.24$ & $4.11 \pm 0.51$ & 0.001 \\
\hline Haptoglobin & $156.20 \pm 54.33$ & $159.82 \pm 59.09$ & 0.731 \\
\hline Fibronectin & $168.56 \pm 98.47$ & $98.24 \pm 74.87$ & 0.0001 \\
\hline TNF & $121.96 \pm 124.83$ & $56.03 \pm 48.39$ & 0.0001 \\
\hline
\end{tabular}




\subsection{Comparison Between Control and Hepatitis B Patients According to Gender}

Table 2 shows the gender contrast between control and hepatitis B patients. In the current study, all variables $(\mathrm{P}<0.05)$ in male and female patients with hepatitis B were substantially different from the control group, with the exception of haptoglobin $(\mathrm{P}>0.05)$.

Table 2. Control and hepatitis B patients data according to sex.

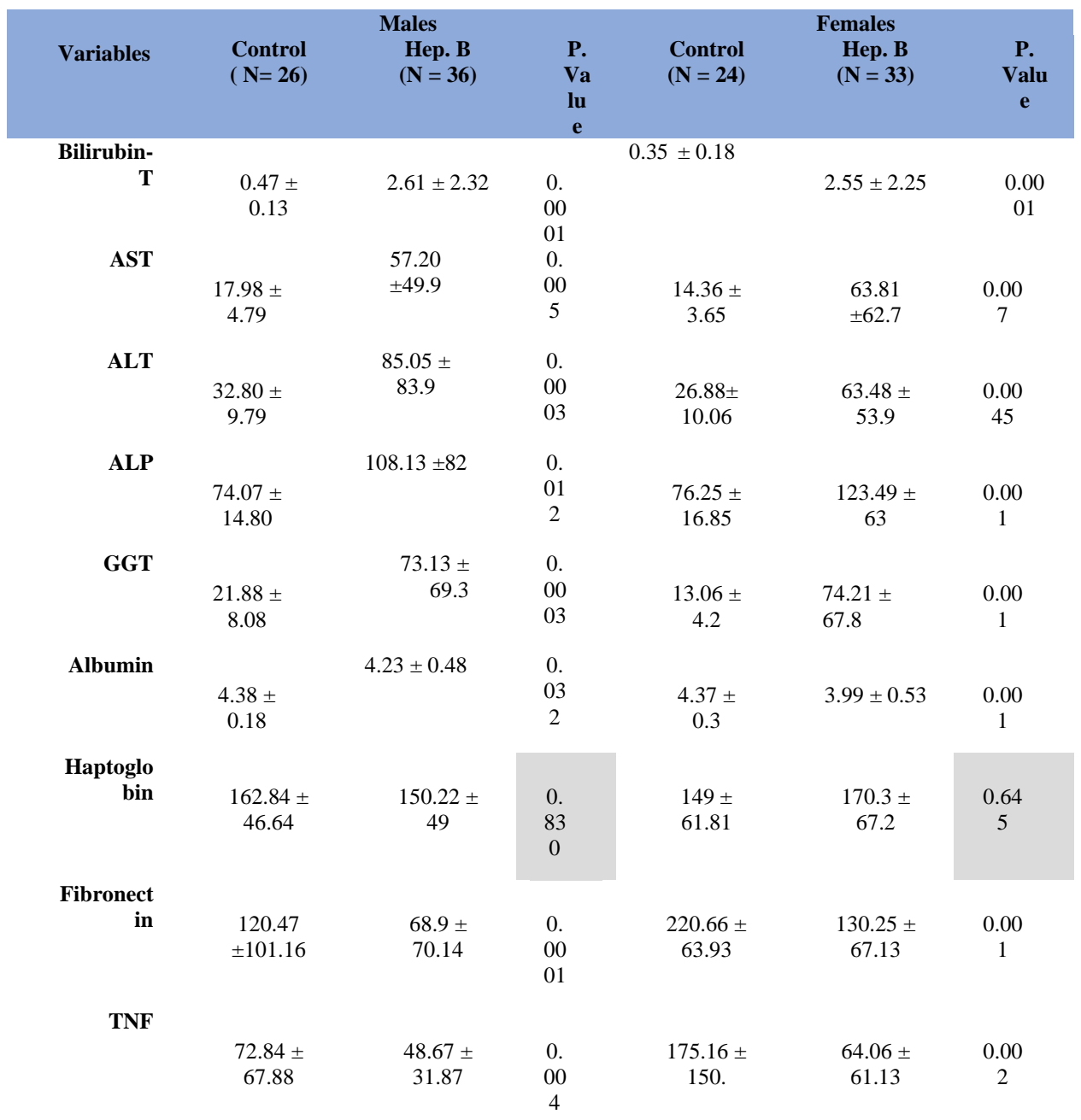

\subsection{ROC Analysis for the Hepatitis B}

Table 3 shows the ROC for the identification of liver fibrosis in hepatitis B. According to the findings of this investigation, fibronectin and TNF had the lowest AUC. 
Table 3. ROC for liver fibrosis detection with hepatitis B.

\begin{tabular}{|l|c|c|c|c|c|c|c|c|}
\hline Variables & $\begin{array}{c}\text { The } \\
\text { area } \\
\text { under } \\
\text { the } \\
\text { ROC } \\
\text { curve }\end{array}$ & $\begin{array}{c}\text { p- } \\
\text { value } \\
(\mathrm{AU} \\
\mathrm{C} 0=0 \\
5)\end{array}$ & $\begin{array}{c}\text { Best } \\
\text { cut-off } \\
\text { criteri } \\
\text { on }\end{array}$ & $\begin{array}{c}\text { Sensitiv } \\
\text { ity (\%) }\end{array}$ & $\begin{array}{c}\text { Specificit } \\
\text { y } \\
(\%)\end{array}$ & $\begin{array}{c}\text { Efficien } \\
\text { cy }\end{array}$ & $\begin{array}{c}\mathrm{P} \\
\mathrm{P} \\
\mathrm{V}\end{array}$ & $\begin{array}{c}\mathrm{N} \\
\mathrm{P} \\
\mathrm{V}\end{array}$ \\
\hline $\begin{array}{l}\text { Haptoglobi } \\
\text { n }\end{array}$ & 0.519 & 0.772 & - & - & - & - & - & - \\
\hline $\begin{array}{l}\text { Fibronecti } \\
\text { n }\end{array}$ & 0.278 & $\begin{array}{c}0.000 \\
1\end{array}$ & & & & - & - & - \\
\hline TNF & 0.374 & 0.020 & - & - & - & - & - & - \\
\hline
\end{tabular}

\subsection{Identification of people with hepatitis B}

According to the findings of this investigation, no parameters had statistically significant differences $(\mathrm{P}>0.05)$. The size of the odds ratios, on the other hand, differed. Table 4 shows that GGT and AST were optimum.

Table 4. Detail of people with hepatitis B who are at risk of developing liver fibrosis.

\begin{tabular}{|c|c|c|c|c|}
\hline \multirow[t]{2}{*}{ Variables } & \multirow{2}{*}{$\begin{array}{c}\text { P. } \\
\text { Value }\end{array}$} & \multirow[t]{2}{*}{ Odd ratio } & \multicolumn{2}{|c|}{ 95\% Confidence Limits } \\
\hline & & & Low & Upper \\
\hline Bilirubin T & 0.917 & 0.0001 & 0.0001 & $*$ \\
\hline AST & 0.966 & 11.781 & 0.0001 & 66.0 \\
\hline ALT & 0.933 & 0.028 & 0.0001 & 1.790 \\
\hline ALP & 0.967 & 0.545 & 0.0001 & 12.000 \\
\hline GGT & 0.959 & 20.141 & 0.0001 & 3.400 \\
\hline Albumin & 0.999 & 0.080 & 0.0001 & $*$ \\
\hline Haptoglobin & 0.930 & 1.939 & 0.0001 & 511.000 \\
\hline Fibronectin & 0.931 & 0.579 & 0.0001 & 12.000 \\
\hline TNF & 0.944 & 1.389 & 0.0001 & 130.0 \\
\hline
\end{tabular}

\subsection{Correlations Patients Results}

Table 5 shows the associations between the factors for patients. A correlation coefficient of 0.6 or higher was regarded significant in this study as an indicator of correlation between binary variables. All other factors were not significant except for ALT and AST. 
Table 5. Correlations over patients.

\begin{tabular}{|c|c|c|c|c|c|c|c|c|c|c|}
\hline & Bilir & A & A & A & G & A & $\mathrm{H}$ & $\mathrm{F}$ & $\mathrm{T}$ & Cho \\
\hline & ubin & $\mathrm{S}$ & $\mathrm{L}$ & $\mathrm{L}$ & G & 1 & ep & $\mathrm{i}$ & $\mathrm{N}$ & leste \\
\hline & \multirow[t]{5}{*}{ D } & $\mathrm{T}$ & $\mathrm{T}$ & $\mathrm{P}$ & $\mathrm{T}$ & $\mathrm{b}$ & at & $\mathrm{b}$ & $\mathrm{F}$ & rol \\
\hline & & & & & & $\mathrm{u}$ & o. & $\mathrm{r}$ & & \\
\hline & & & & & & $\mathrm{m}$ & & o & & \\
\hline & & & & & & $\mathrm{i}$ & & $\mathrm{n}$ & & \\
\hline & & & & & & $\mathrm{n}$ & & & & \\
\hline Bilir & \multirow[t]{4}{*}{0.92} & 0 & 0 & $\mathbf{0}$ & $\mathbf{0}$ & 0 & 0. & 0 & 0 & 0.16 \\
\hline ubin & & . & . & . & . & . & $\mathbf{0}$ & . & . & \\
\hline \multirow[t]{2}{*}{$\mathrm{T}$} & & 4 & 5 & 4 & 2 & 2 & 6 & 0 & 0 & \\
\hline & & 6 & 8 & 0 & 2 & 5 & & 8 & 7 & \\
\hline AS & & 1 & 0 & 0 & 0 & 0 & 0. & 0 & 0 & 0.08 \\
\hline \multirow[t]{3}{*}{$\mathrm{T}$} & & & . & . & . & . & $\mathbf{0}$ & . & . & \\
\hline & & & 6 & 3 & 4 & 1 & 2 & 1 & 1 & \\
\hline & & & 3 & 8 & $\mathbf{0}$ & 5 & & 3 & 0 & \\
\hline \multirow{4}{*}{$\begin{array}{r}\mathrm{AL} \\
\mathrm{T}\end{array}$} & & & 1 & 0 & $\mathbf{0}$ & 0 & 0. & 0 & 0 & 0.13 \\
\hline & & & & . & . & . & $\mathbf{0}$ & . & . & \\
\hline & & & & 3 & 3 & 1 & 4 & 0 & 0 & \\
\hline & & & & 5 & 1 & 5 & & 8 & 7 & \\
\hline \multirow{4}{*}{$\begin{array}{r}\mathrm{AL} \\
\mathrm{P}\end{array}$} & & & & 1 & $\mathbf{0}$ & 0 & 0. & 0 & 0 & 0.12 \\
\hline & & & & & . & . & $\mathbf{0}$ & . & . & \\
\hline & & & & & 5 & 4 & 3 & 0 & 0 & \\
\hline & & & & & 2 & 0 & & 9 & 6 & \\
\hline \multirow{4}{*}{$\begin{array}{r}\mathrm{GG} \\
\mathrm{T}\end{array}$} & & & & & 1 & 0 & 0. & 0 & 0 & 0.09 \\
\hline & & & & & & . & 0 & . & . & \\
\hline & & & & & & 3 & 1 & 1 & 1 & \\
\hline & & & & & & 6 & & 7 & 2 & \\
\hline \multirow{4}{*}{$\begin{array}{r}\text { Alb } \\
\text { umi } \\
\mathrm{n}\end{array}$} & & & & & & 1 & 0. & 0 & 0 & 0.01 \\
\hline & & & & & & & 0 & . & . & \\
\hline & & & & & & & 8 & 1 & 0 & \\
\hline & & & & & & & & 0 & 9 & \\
\hline \multirow{4}{*}{$\begin{array}{l}\text { Hep } \\
\text { ato. }\end{array}$} & & & & & & & 1 & 0 & 0 & 0.01 \\
\hline & & & & & & & & . & . & \\
\hline & & & & & & & & 0 & 0 & \\
\hline & & & & & & & & 6 & 2 & \\
\hline \multirow{4}{*}{$\begin{array}{l}\text { Fibr } \\
\text { one } \\
\text { ctin }\end{array}$} & & & & & & & & 1 & 0 & 0.12 \\
\hline & & & & & & & & & • & \\
\hline & & & & & & & & & 7 & \\
\hline & & & & & & & & & 2 & \\
\hline TN & & & & & & & & & 1 & 0.02 \\
\hline
\end{tabular}

\section{Discussion}

The deposition of ECM produced by HSC and other hepatic cells is directly involved in liver fibrosis markers, as well as indirect liver function assessments. Hepatic injury is linked to a disruption of several metabolic activities, that helps with the biochemical analysis of liver illness. The current study revealed the haptoglobin in HBV patients (159.82) was a nonsignificant difference when compared with control, this result appeared due to begin to decrease the haptoglobin concentration after it was elevated at the onset of infection because 
of the progress of hepatocyte damage and synthesis of fibrosis this result was an agreement with [5]. The fibronectin levels in hepatitis B were significant low (98.24) compared with control, the decreased level of fibronectin due to decrease releasing from hepatocytes in patients with chronic hepatitis this result was an agreement with [6], the fibronectin serum level increases with the advancement of liver fibrosis but finally decreases in patients with cirrhosis due to hepatic dysfunction which agreement with [7] and [8]. In dendritic cells, the viral core proteins induce immunological tolerance and overproduce IL-10, which can suppress the production of pro-inflammatory cytokines. The viral core proteins, which induce immunological tolerance in dendritic cells and overproduce IL-10, which can suppress the production of pro-inflammatory cytokines, appeared to be responsible for this result (TNF- $\alpha$ ). The result was an agreement with [9]. The current study revealed the mean of haptoglobin, fibronectin, and TNF alpha in the male $(150.22,68.9,48.67)$ respectively lower than female this indicter the liver fibrosis in the male more progress than female, this result agreement with [10]. Estrogens are important for preserving homeostasis and making the liver less vulnerable to a variety of chronic liver disorders, according to [11]. Feminine immune responses are greater than male immune responses in adulthood, which resulting in a decreased risk of infection and a superior ability to clear viral infection in women, according to [12]. ROC curves are used to diagnose liver fibrosis caused by hepatitis B. The results showed that haptoglobin, fibronectin, and TNF had an area under the ROC less than 0.6, therefore sensitivity and specificity could not be calculated. The risk of liver fibrosis was determined using multivariable logistic regression analysis. The outcomes were shown that some variables in the model were non-significant $(\mathrm{P}$ value $>0.05$ ), but the odds ratios in these parameters are more risk compared with other parameters, this result is an agreement with [13].

\section{Conclusion}

Hepatic fibrosis can be predicted directly and indirectly using direct and non-invasive biochemical markers in patients with chronic hepatitis B virus, as well as the progression and management of fibrosis.

\section{References}

[1] Vasimahmed Lala, Amandeep Goyal, Pankaj Bansal and David A. Minter, 2021, Liver Function Tests, StatPearls ; 12.

[2] Morini, S., Carpino, G., Carotti, S., \& Gaudio, E. (2020). Anatomy and Embryology of the Liver. In Liver Diseases Springer. (pp. 3-16).

[3] Marc Ringehan, Jane A. McKeating and Ulrike Protzer, 2017, Viral hepatitis and liver cancer, journal the royal society.

[4] Joon-Il Jun and Lester F. Lau, 2018 , Resolution of organ fibrosis , the journal of clinical investigation ; 128(1):97-107

[5] Erturk, Erkan, Ozkurt, Parlak \& Cure, M. C. (2014). Serum fibronectin levels in acute and chronic viral hepatitis patients. The Malaysian Journal of Medical Sciences, 21(1): 29.

[6] Safaei, Oskouie, Mohebbi, Razaghi, Z., \& Nejadi, N. (2020). Proteomic study of advanced cirrhosis based on HCV to reveal potential biomarkers. Gastroenterology and Hepatology From Bed to Bench, 13(1):113.

[7] Younesi, S., \& Parsian, H. (2019). Diagnostic accuracy of glycoproteins in the assessment 
of liver fibrosis: A comparison between laminin, fibronectin, and hyaluronic acid. The Turkish Journal of Gastroenterology, 30(6): 524.

[8] Sarvari, Mojtahedi, Kuramitsu, Malek-Hosseini; et al (2011). Differential expression of haptoglobin isoforms in chronic active hepatitis, cirrhosis and HCC related to HBV infection. Oncology Letters, 2(5): 871-877.

[9] Rosen, H. R., \& Golden-Mason, L. (2020). Control of hev infection by natural killer cells and macrophages. Cold Spring Harbor Perspectives in Medicine, 10(9).

[10] Jamal Sarvari, Zahra Mojtahedi, Yasuhiro Kuramitsu and Seyed-Ali Malek-Hosseini 2011, Differential expression of haptoglobin isoforms in chronic active hepatitis, cirrhosis and HCC related to HBV infection, Oncology Letters, 2(5): 871-877

[11] Ezhilarasan, D. (2020). Critical role of estrogen in the progression of chronic liver diseases. Hepatobiliary \& Pancreatic Diseases International, 19( 5): 429-434

[12] Henze, L., Schwinge, D., \& Schramm, C. (2020). The Effects of Androgens on T Cells: Clues to Female Predominance in Autoimmune Liver Diseases? Frontiers in Immunology, 11:1567.

[13] Karsdal, Morten A, Hjuler, Rasmussen;et.al (2019). Assessment of liver fibrosis progression and regression by a serological collagen turnover profile. American Journal of Physiology-Gastrointestinal and Liver Physiology, 316(1): 25-31. 